\title{
1 Development of a public audiology service in Southern Malawi: 2 Profile of patients across two years.
}

3

Bhavisha Parmar a, Mwanaisha Phiri ${ }^{\mathrm{b}}$, Courtney Caron ${ }^{\mathrm{c}}$, Tess Bright ${ }^{\mathrm{d}}$ and Wakisa Mulwafu ${ }^{\mathrm{e}}$

a UCL Ear Institute, University College London, 332-336 Grays Inn Road, London, WC1X 8EE, UK

${ }^{b}$ Queen Elizabeth Central Hospital, Blantyre, Malawi

${ }^{c}$ Veterans Health Administration, Veterans Affairs Southern Nevada Health Care System, Audiology Clinic, 6900

North Pecos Road, North Las Vegas, NV 89086, USA

${ }^{d}$ International Centre for Evidence in Disability, London School of Hygiene \& Tropical Medicine, Keppel St,

London, WC1 E7HT, UK

e Department of Surgery, College of Medicine, University of Malawi, Blantyre, Malawi

Corresponding author: bhavisha.parmar@ucl.ac.uk

\section{Abstract}

Objective: To describe the profile of patients attending the Queen Elizabeth Central Hospital (QECH) audiology clinic in Malawi, over a two-year period (2016-2017).

Design: A retrospective patient record review.

Study sample: There were 2299 patients assessed at the QECH audiology department between January 2016 to December 2017. Adult patients' ages ranged from 18 to 94 years $(M=45.8$, $S D=19.22)$. The mean age of children included in this study was 7.7 years $(S D=5.21)$. Overall, $45.4 \%$ of patients were female.

Results: Of the $61.6 \%$ of adults and $41.7 \%$ of children found to have some degree of hearing loss, $28.3 \%$ and $15.4 \%$ were fitted with hearing aids, respectively. The number of patients seen in 2017 $(n=1385)$ was $34 \%$ higher than that of $2016(n=914)$.

Conclusion: This study found that demand for hearing services is increasing in this Malawian Audiology department but uptake of hearing aids for those in need is low. Future evaluation of service provision and treatment outcomes is needed. Results from this study can be used to inform the development of future audiology clinics in low resource settings. 
Introduction

It is estimated that 466 million people in the world live with disabling hearing loss [1]. Over $80 \%$ of people with disabling hearing loss live in low- and middle- income countries (LMICs) [2]. The prevalence of hearing loss may be higher in LMICs due to the burden of infectious diseases, poorer access to health care and ear protection as well as increased use of unregulated ototoxic medications $[3,4]$. It has been reported that public health measures could reduce the global prevalence of hearing loss by $50 \%$ in LMICs [5].

Unaddressed hearing loss can have a significant impact on an individual's communication, cognition, education, employment and overall wellbeing [6-9]. However, there are many barriers to addressing hearing loss in LMICs. Some of these include the access to ear and hearing services, including assistive technologies such as hearing aids or cochlear implants [5]. Of the 401 million people that need hearing aids globally, approximately $83 \%$ either do not use or have access to them. This increases to $90 \%$ for people residing in African countries [10]. Some significant barriers to the development of ear and hearing care services in these regions include the lack of local training opportunities and a dearth of contextual data regarding the prevalence and aetiology of hearing loss [11], alongside the lack of appropriate policy efforts needed to allocate the necessary resources [10].

Malawi is a landlocked country in Southern Africa with a population of approximately 17.5 million [12]. It is classified as a low income country by the World Bank [13] The WHO estimates $4-5 \%$ of the population of sub-Saharan Africa is estimated to have a disabling hearing loss [14]. However, data on the prevalence and causes of hearing loss in the vast majority of countries in sub-Saharan Africa, including Malawi is very limited. A systematic review by Mulwafu et al (2016) investigated the prevalence of hearing loss in the region and found only eight population-based studies with others relying on data from school screening programmes [15]. Hunt et al (2017) carried out a communitybased study in rural Malawi and reported a high prevalence of hearing loss in children aged 4-6 years (11.5\%) [16]. A recent population- based longitudinal analysis of children with hearing loss in two districts of rural Malawi compared baseline assessment data obtained in 2013 with follow up data from 2016 [17]. The study found that over half of all children diagnosed with hearing loss (59.1\%) were lost 
to follow up and there was a low onward referral uptake, particularly for girls and younger children. Similarly, Bright et al (2017) found that $93 \%$ of children identified as needing ear and hearing care services in Southern Malawi could not attend their referral appointment [18].

A 2015 survey of Ear Nose and Throat (ENT) services revealed that Malawi, Kenya and South Africa have $0.1,2$, and 5.6 ENT surgeons per million, respectively [19]. When compared to the United Kingdom, where evidence suggests there are 24 ENT surgeons per million people, these numbers demonstrate the huge scarcity of human resources in the region [19]. There are currently three ENT surgeons and three audiologists [20,21] in Malawi. The majority of ear and hearing care services are only available in urban areas and outreach support is provided to rural areas. This paper focusses on audiology services provided at Queen Elizabeth Central Hospital $(\mathrm{QECH})$, Malawi's largest tertiary referral hospital located in Blantyre, Southern Malawi.

The Development of QECH Audiology Department, Blantyre, Malawi

The first resident ENT surgeon began work at QECH in 2007 [22]. sln 2010 he developed a cadre of ENT clinical officers to work at central and district hospitals. This initiative encouraged the use of task shifting to overcome the significant shortage of specialised health professionals A diploma in 'ENT and Audiology' was introduced to advance the training of clinical officers (secondary school graduates with a diploma in clinical medicine) [23].

Recognising the need for audiology services in the country, in 2014, Sound Seekers began work in Malawi to develop the audiology services and work alongside the pre-existing ENT services. Sound Seekers is a UK registered charity, established in 1959, which aims to "deliver practical solutions to support people with hearing loss to realise their rights by enabling access to healthcare and education" [24].

In November 2015, Sound Seekers signed a Memorandum of Understanding with the Malawian Ministry of Health $(\mathrm{MoH})$ to work with $\mathrm{QECH}$ to advance audiology services. This ensured commitment and awareness of the need for ear and hearing care services at a government level and outlined the 
objectives of both parties. Sound Seekers agreed to manage the construction of the clinic, establish the services and train personnel whilst the $\mathrm{MoH}$ committed to maintaining the services after the withdrawal of Sound Seekers' support and ensure the trained personnel were employed within the department with job roles corresponding to the relevant, specialist training they had received.

In 2015, with three-year funding from the UK Department for International Development (DFID) and Jersey Overseas Aid (JOA), Sound Seekers fully set up audiology services in QECH, including both clinic and outreach services. With the support of the MoH, the QECH Audiology department was opened in 2016. An experienced volunteer audiologist from the United States (CC) was appointed by Sound Seekers from 2015 - 2018 to manage the audiology clinic and train the new audiology staff at QECH.

Sound Seekers funded the training of the first two Malawian audiologists who successfully completed their Masters level (MSc) Audiology training at the University of Manchester (UK) in 2015. At the time of writing, there is one audiologist, five audiology officers, one ear mould technician and an office manager employed by the QECH audiology clinic. Audiology officers are nurses or clinical officers who have received diploma qualifications in audiology or hearing aid acoustics. In April 2018, the volunteer Audiologist handed the management and operations of the clinic and outreach services to the Malawian audiologists, Following completion of the project, all services were handed over to QECH in April 2019. Since the handover, as committed by the $\mathrm{MoH}$, the clinic services continue. However, outreach services have been limited to periods when there is funding available either through the hospital or external organisations.

All clinical equipment to render comprehensive audiological services were procudred with funding from donations to Sound Seekers. Audiologists and audiology officers at QECH provide diagnostic testing for patients of all-ages including: pure tone audiometry (PTA), visual reinforcement audiometry (VRA), auditory brainstem response (ABR), auditory steady state response (ASSR) and otoacoustic emissions (OAE). 9

For each clinical assessment, a detailed history is taken, followed by ear examination and formal audiological assessment. Occluding ear wax and/or foreign bodies are removed from the ear canal 
before the hearing assessment. Intervention options at the service include hearing aid fittings, ear wax removal and onward referral to ENT and other specialist services.

Hearing aid provision at QECH, and in Malawi more broadly, is mostly donor dependent. In 2015, a 'Hearing Aid Refurbishment Programme (HARP)' was established by Sound Seekers. The HARP supports a small audiology lab based in Zambia to refurbish digital hearing aids donated from individuals and hospitals in the UK. Refurbished hearing aids are then distributed to all Sound Seekers project countries and custom ear moulds are made at each site. The QECH audiology department generates limited income through health insurance payments and patient fees for services and hearing aids. Those that cannot pay receive services without cost. There are no local providers of ear mould materials but QECH audiology clinic has been able to overcome this challenge by using locally available, low cost dental alginate for ear impressions and dental acrylic to create the custom ear moulds. The clinicians have also collaborated with the QECH's bioengineering department to make some of the consumables locally thus reducing the cost of the entire ear mould manufacturing process.

In association with other international charities, visiting ENT surgeons and a cochlear implant manufacturer (MED-EL), 17 children identified with severe to profound hearing loss have successfully received a cochlear implant since 2015 with follow up care provided at QECH audiology department [25]. In addition to clinic-based services, the clinic runs an outreach programme to districts in the Southern province of Malawi where patients are screened, simple treatments provided, hearing aids fitted and referrals made for more complex cases. A sound proofed hearing assessment and research clinic (HARK) vehicle is used for assessments during outreach activities. The audiology service has also developed a bespoke patient database, presenting an opportunity to analyse the profile of patients attending the clinic. Every patient's demographic and clinical data is recorded onto an Excel data collection sheet specifically designed to collate and facilitate analysis of data. Demographic data is collected including gender, place of residence and age. Clinical data includes information pertinent to potential causes of hearing loss, type of assessment carried out, clinical findings and interventions. Throughout the development of the clinic, audiology staff received data collection training and support from Sound Seekers to ensure the data was collected reliably and recorded accurately. 
153 The World Health Assembly resolution on the prevention of deafness and hearing loss (WHA70.13),

154 published in May 2017, provided nine action points for member states [26]. This research article is

155 able to provide potential approaches for the following: "to integrate strategies for ear and hearing care

156 within the framework of their primary health care system" and "to improve access to affordable, cost-

157 effective, high-quality, assistive hearing technologies and products, including hearing aids".

158 Specifically, we focus on the development of the QECH audiology department and the profile of

159 patients attending the clinic in the first two years of the service.

160

161

162

163

164

165

166

167

168

169

170

171

172

173

174

175

176

177

178

179

180

181

\section{Methods}

\section{Study design}

A retrospective patient record review of patient's assessed at the $\mathrm{QECH}$ audiology department between January 2016 and December 2017 was conducted. A convenience sampling approach was taken to include all new patients, seen within QECH audiology department between January 2016 and December 2017 in the study sample.

\section{Participants}

A total of 2299 patients, 1521 adults and 778 children, were assessed at the QECH audiology department between January 2016 and December 2017. Adult patients' ages ranged from 18 to 94 years $($ Mean $=45.8, S D=19.22)$. The mean age of children included in this study was 7.7 years $(S D=$ 5.21). Overall, $45.4 \%$ of patients identified as female.

\section{Data collection procedures}

Demographic and clinical data was extracted from the department's clinical records excel spreadsheet including patterns of diagnosis and interventions.

\section{Definitions}

The World Health Organization (WHO) definition of disabling hearing loss and hearing loss grading system was used to characterise each patient's hearing loss [1]. 
182 As the database described the configuration and degree of hearing loss qualitatively rather than specifying the actual pure tone average threshold of each ear, the following assumptions were made around the degree of loss for the purposes of reporting in this study:

The type of hearing loss was coded according to the better ear and in line with the WHO definitions [27].

\section{Ethical considerations}

This study was approved by the College of Medicine Research and Ethics Committee (COMREC), University of Malawi (P.04/17/2153). No patient identifiable data was extracted or presented in this study.

Data analysis was conducted in Stata (version 15.0) to arrange the data and give basic descriptive statistics (mean and standard deviation). $R$ version 3.6.1 was used to perform a binary logistic regression analysis to predict year (2016 vs. 2017) in which a patient was examined from categorical variables described that patient: age (child, adult); sex (female, male); hearing loss diagnosis (yes, no); recommended intervention; degree of hearing loss. Patient demographics included age, gender and location. The main study outcomes included type of diagnostic assessment, degree and type of hearing loss and type of audiological intervention offered. Results for adults and children were disaggregated for each of the outcomes. 
Results

215 The number of patients assessed in $2017(n=1385)$ was $34 \%$ higher than that of $2016(n=914)$. In terms of locality, $83 \%$ of patients originated from the Southern region of Malawi, with $8.8 \%$ from other Malawian regions and $1.3 \%$ were from other countries (the location data was only available for patients seen in 2016). Over the two-year period, $41.7 \%$ of children and $61.6 \%$ of adults attending the clinic were found to have some degree of hearing loss (Table 1).

Table 1. Patients with hearing loss according to age group

\begin{tabular}{|c|c|}
\hline $\begin{array}{c}\text { Age category } \\
\text { (years) }\end{array}$ & $\begin{array}{c}\text { Total number of patients with } \\
\text { hearing loss } \\
\text { Total \% }(\mathbf{n}) \\
(\mathbf{n}=\mathbf{1 2 6 2})\end{array}$ \\
\hline $\mathbf{0 - 5}$ & $6.6(83)$ \\
\hline $\mathbf{6 - 1 0}$ & $7.5(95)$ \\
\hline $\mathbf{1 1 - 1 7}$ & $11.7147)$ \\
\hline $\mathbf{1 8 - 2 9}$ & $17.9(226)$ \\
\hline $\mathbf{3 0 - 3 9}$ & $13.6(171)$ \\
\hline $\mathbf{4 0 - 4 9}$ & $8.9(112)$ \\
\hline $\mathbf{5 0 - 5 9}$ & $8.8(111)$ \\
\hline $\mathbf{6 0 - 6 9}$ & $11.9(150)$ \\
\hline $\mathbf{7 0 - 7 9}$ & $7.5(94)$ \\
\hline $\mathbf{8 0 +}$ & $5.8(73)$ \\
\hline
\end{tabular}

232

Of those with hearing loss, $80.9 \%$ of children and $77.0 \%$ of adults with hearing loss presented with a bilateral hearing loss. Sensorineural hearing loss was the most common type of loss affecting $66.8 \%$ of children and $67.8 \%$ of adults with hearing loss. Conductive hearing loss was present in $20 \%$ of children and $13.9 \%$ of adults with hearing loss. Table 2 describes the type, degree and laterality of hearing losses found in paediatric and adult patients assessed at QECH over the two-year period. 


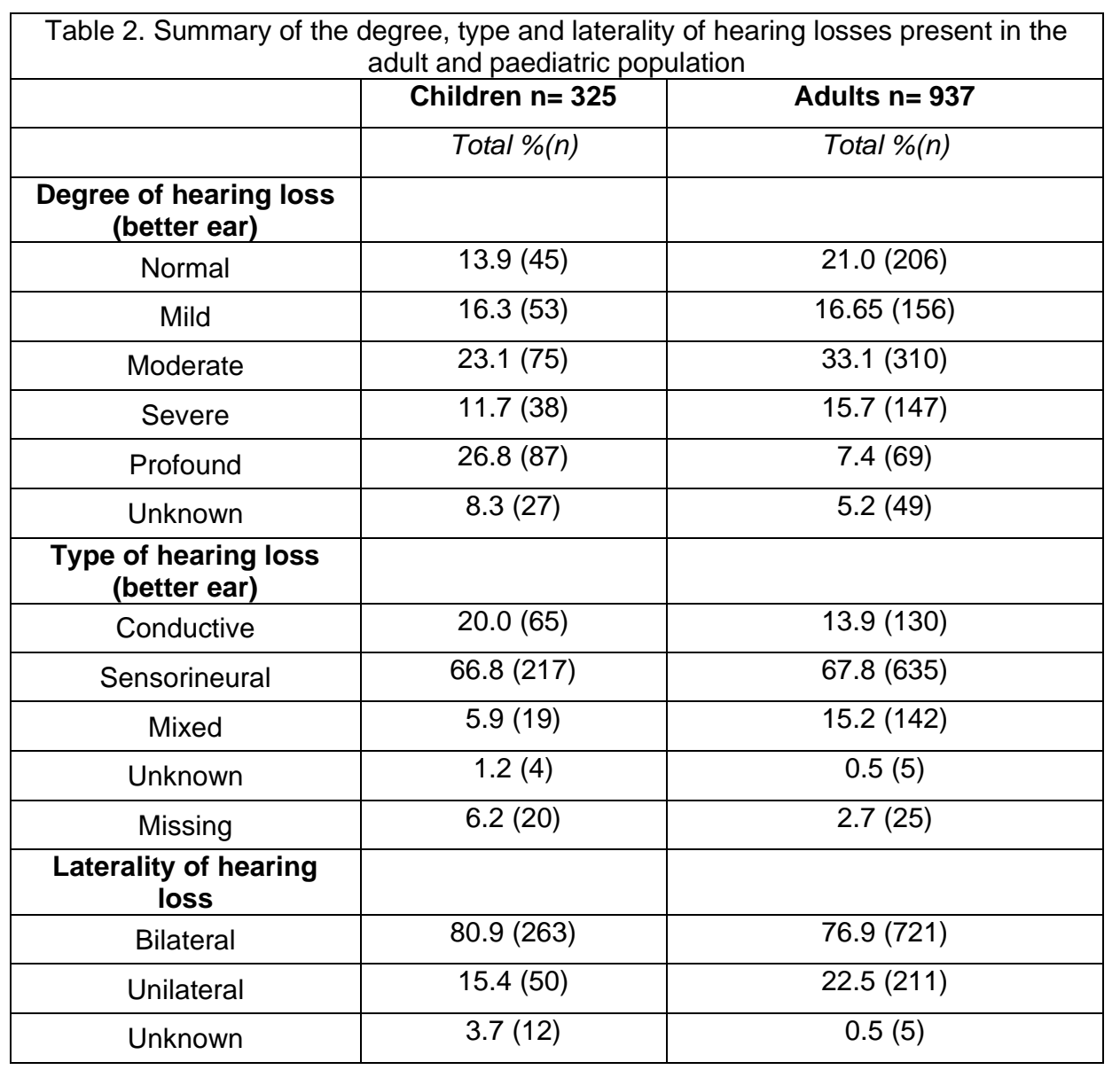

Table 3 highlights the causes of hearing loss in adults in children assessed at QECH. Overall, $18.5 \%$ of children with hearing loss presented with chronic suppurative otitis media (CSOM) and $8.6 \%$ had a history of ototoxic medication administration. Presbyacusis was a major cause of hearing loss in adults (19.7\%). CSOM was the cause for $14.4 \%$ of adults. The cause of hearing loss was unknown for $56.7 \%$ of adults with hearing loss, and $65.9 \%$ among children.

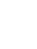

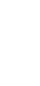


Table 3. Suspected causes of hearing loss for children and adult patient's diagnosed with hearing loss in January 2016- December 2017

\begin{tabular}{|c|c|c|}
\hline $\begin{array}{c}\text { Suspected cause of } \\
\text { hearing loss }\end{array}$ & $\begin{array}{c}\text { Children \%(n) } \\
\mathbf{n = 3 2 5}\end{array}$ & $\begin{array}{c}\text { Adults \%(n) } \\
\mathbf{n}=937\end{array}$ \\
\hline ANSD & $0.6(2)$ & $0.1(1)$ \\
\hline CSOM & $18.8(61)$ & $14.4(135)$ \\
\hline Malaria & $0.9(3)$ & 0 \\
\hline Meningitis & $1.9(6)$ & $1.1(11)$ \\
\hline Mumps & $0.9(3)$ & $0.1(1)$ \\
\hline OME & $2.2(7)$ & $2.1(20)$ \\
\hline Ototoxicity & $8.6(29)$ & $3.5(33)$ \\
\hline Presbyacusis & 0 & $19.7(185)$ \\
\hline Tuberculosis & 0 & $1.3(12)$ \\
\hline Trauma & $0.3(1)$ & $0.8(7)$ \\
\hline Noise & 0 & $0.1(1)$ \\
\hline Unknown & $65.9(214)$ & $56.7(531)$ \\
\hline
\end{tabular}

ANSD: Auditory Neuropathy Spectrum Disorder CSOM: Chronic Suppurative Otitis Media OME: Otitis Media with Effusion

PTA was the most commonly used assessment method in 2016 and 2017 and was performed on $50 \%$ electrophysiological methods increased from 20 patients in 2016 to 66 patients in 2017 . The use of OAEs also increased from 187 patients in 2016 to 452 in 2017. VRA and play audiometry were reported to have only been used to assess a combined total of 32 patients across both years. Tympanometry was carried out on $84 \%$ of patients to assess middle ear function.

Table 4. Type of audiological assessment carried out for patients with and without hearing loss in 2016 and 2017.

\begin{tabular}{|c|c|c|c|c|c|c|}
\hline \multirow{2}{*}{ Type of assessment } & \multicolumn{2}{|c|}{$\begin{array}{c}\text { Patients with hearing loss } \\
\mathrm{n}=1262\end{array}$} & $\begin{array}{c}\text { Patients without hearing } \\
\text { loss } \\
\mathrm{n}=1037\end{array}$ & $\begin{array}{c}\text { Total Patients } \\
2016 \\
\mathrm{n}=914\end{array}$ & $\begin{array}{c}\text { Total Patients } \\
2017 \\
\mathrm{n}=1385\end{array}$ \\
\hline & $\begin{array}{c}\mathbf{2 0 1 6} \\
\%(\mathrm{n})\end{array}$ & $\begin{array}{c}\mathbf{2 0 1 7} \\
\%(\mathrm{n})\end{array}$ & $\begin{array}{c}\mathbf{2 0 1 6} \\
\%(\mathrm{n})\end{array}$ & $\begin{array}{c}\mathbf{2 0 1 7} \\
\%(\mathrm{n})\end{array}$ & $\begin{array}{c}\mathbf{2 0 1 6} \\
\%(\mathrm{n})\end{array}$ & $\begin{array}{c}\mathbf{2 0 1 7} \\
\%(\mathrm{n})\end{array}$ \\
\hline $\begin{array}{c}\text { Pure tone } \\
\text { audiometry (PTA) }\end{array}$ & $79.8(423)$ & $59.8(438)$ & $35.7(137)$ & $25.0(163)$ & $61.3(560)$ & $43.4(601)$ \\
\hline Play audiometry & $0.2(1)$ & $0.6(4)$ & $0.3(1)$ & $0.2(1)$ & $0.2(2)$ & $0.4(5)$ \\
\hline VRA & $0.2(1)$ & $0.3(2)$ & $3.1(12)$ & $1.5(10)$ & $1.4(13)$ & $0.9(12)$ \\
\hline OAE & $15.7(83)$ & $31.3(229)$ & $27.1(104)$ & $34.2(223)$ & $20.5(187)$ & $32.6(452)$ \\
\hline ABR & 0 & $0.1(1)$ & $0.3(1)$ & $0.8(5)$ & $0.1(1)$ & $0.43(6)$ \\
\hline
\end{tabular}




\begin{tabular}{|c|c|c|c|c|c|c|}
\hline ASSR & $3.6(19)$ & $5.9(43)$ & 0 & $2.7(17)$ & $2(19)$ & $4.3(60)$ \\
\hline Data missing & $0.6(3)$ & $2.0(15)$ & $33.6(129)$ & $35.8(234)$ & $14.4(132)$ & $17.9(249)$ \\
\hline
\end{tabular}

VRA: Visual Reinforcement Audiometry, OAE: Otoacoustic Emissions, ABR: Auditory Brainstem Response, ASSR: Auditory Steady State Response

Table 5 summarises the recommended interventions for patients diagnosed with hearing loss. In 2016, $21.6 \%$ of children with hearing loss were fitted with hearing aids, compared to $12 \%$ in 2017 . Similarly, 39.4\% of adults with hearing loss were fitted with hearing aids in 2016 and this decreased to 19.5\% in 2017 (Table 5). Referrals to ENT increased over time. In 2016, 16.4\% of children with hearing loss and $9.9 \%$ of adults with hearing loss were referred to ENT compared to $21.5 \%$ and $17.2 \%$, respectively in 2017 . A further $11.4 \%$ of children with hearing loss were referred to a deaf school or special education resource unit and $10.5 \%$ were recommended to have sign language training. In order to statistically analyse the differences observed between the 2016 and 2017 patient cohorts, a binary logistic regression was performed, predicting year (2016 vs. 2017) in which a patient was examined from categorical variables described that patient: age (child, adult); sex (female, male); hearing loss diagnosis (yes, no); recommended intervention; degree of hearing loss. . All two-way interactions were included in the model to account for any differences in the distribution across various levels of the categorical variables across the two years that should be attributed to other non-significant differences in category membership. In this model, there were only two coefficients that were significant predictors of year, other than the intercept, and both pertained to recommended intervention (Table 5). The binomial variable indicating that sign language training was recommended $(z=2.781, p=0.00542)$ and the variable indicating that the patient was fitted with a hearing aid $(z=-2.381, p=0.0173)$ were the two significant predictors of the year in which a given patient was treated in the logistic regression model. The proportion of patients with hearing loss that were referred to sign language training increased by 4.6\% from 2016 to 2017 . There was a $12 \%$ decrease in the proportion of patients with hearing loss that were fitted with hearing aids from 2016 to 2017. 01 
Table 5. Recommended interventions for patients diagnosed with hearing loss

$p$-value column indicates the significance of the main effect of the individual treatment management plan variables, as regressors in a logistic regression, modeling the probability of a given observation being drawn from the 2016 vs. the 2017 sample.

$* p<.05$. ** $p<.01$.

— indicates data not included in the logistic regression

\begin{tabular}{|c|c|c|c|c|c|c|c|c|c|c|}
\hline \multirow[b]{2}{*}{ Individual Management Plan } & \multicolumn{3}{|c|}{ Children $(\mathrm{n}=325)$} & \multicolumn{3}{|c|}{ Adults $(n=937)$} & \multicolumn{4}{|c|}{ Combined $(\mathrm{n}=1262)$} \\
\hline & $\begin{array}{r}2016 \\
\%(\mathrm{n}) \\
\end{array}$ & $\begin{array}{l}2017 \\
\%(\mathrm{n}) \\
\end{array}$ & $\begin{array}{l}\text { Both } \\
\%(\mathrm{n}) \\
\end{array}$ & $\begin{array}{l}2016 \\
\%(\mathrm{n}) \\
\end{array}$ & $\begin{array}{l}2017 \\
\%(\mathrm{n}) \\
\end{array}$ & $\begin{array}{l}\text { Both } \\
\%(\mathrm{n}) \\
\end{array}$ & $\begin{array}{l}2016 \\
\%(\mathrm{n}) \\
\end{array}$ & $\begin{array}{l}2017 \\
\%(\mathrm{n}) \\
\end{array}$ & $\begin{array}{l}\text { Both } \\
\%(\mathrm{n}) \\
\end{array}$ & $\mathrm{p}$-value \\
\hline Review in audiology & $16.4(19)$ & $19.6(41)$ & $18.5(60)$ & $18.4(76)$ & $16.8(88)$ & $17.5(164)$ & $17.9(95)$ & $17.6(129)$ & $17.7(224)$ & - \\
\hline Hearing aid fitted & $21.6(25)$ & $12(25)$ & $15.4(50)$ & $39.4(163)$ & $19.5(102)$ & $28.3(265)$ & $35.5(188)$ & $17.3(127)$ & $25(315)$ & $0.017 *$ \\
\hline Hearing aid recommended & $15.5(18)$ & $13.4(28)$ & $14.2(46)$ & $14.7(61)$ & $30(157)$ & $23.3(218)$ & $14.9(79)$ & $25.3(185)$ & $20.9(264)$ & 0.553 \\
\hline Medication & $0(0)$ & $1.91(4)$ & $1.23(4)$ & $0(0)$ & $3.25(17)$ & $1.81(17)$ & $0(0)$ & $2.87(21)$ & $1.66(21)$ & 0.990 \\
\hline Refer to Ear, Nose, Throat & $16.4(19)$ & $21.5(45)$ & $19.7(64)$ & $9.9(41)$ & $17.2(90)$ & $14(131)$ & $11.3(60)$ & $18.4(135)$ & $15.5(195)$ & 0.973 \\
\hline Refer to Deaf school & $17.2(20)$ & $8.13(17)$ & $11.4(37)$ & $1.21(5)$ & $0.191(1)$ & $0.64(6)$ & $4.72(25)$ & $2.46(18)$ & $3.41(43)$ & 0.896 \\
\hline Refer elsewhere & $1.72(2)$ & $3.35(7)$ & $2.77(9)$ & $0(0)$ & $0(0)$ & $0(0)$ & $0.377(2)$ & $0.956(7)$ & $0.713(9)$ & 0.573 \\
\hline Recommend sign language training & $3.45(4)$ & $14.4(30)$ & $10.5(34)$ & $2.66(11)$ & $5.16(27)$ & $4.06(38)$ & $2.83(15)$ & $7.79(57)$ & $5.71(72)$ & $0.005 * *$ \\
\hline Recommend speech therapy & $0(0)$ & $0.957(2)$ & $0.615(2)$ & $0(0)$ & $0(0)$ & $0(0)$ & $0(0)$ & $0.273(2)$ & $0.158(2)$ & 0.993 \\
\hline Tinnitus counselling & $0(0)$ & $0(0)$ & $0(0)$ & $0.725(3)$ & $2.1(11)$ & $1.49(14)$ & $0.566(3)$ & $1.5(11)$ & $1.11(14)$ & 0.988 \\
\hline Other & $0(0)$ & $0(0)$ & $0(0)$ & $0.725(3)$ & $0.765(4)$ & $0.747(7)$ & $0.566(3)$ & $0.546(4)$ & $0.555(7)$ & 0.781 \\
\hline No further action & $7.76(9)$ & $4.78(10)$ & $5.85(19)$ & $11.8(49)$ & $4.97(26)$ & $8(75)$ & $10.9(58)$ & $4.92(36)$ & $7.45(94)$ & 0.106 \\
\hline Data missing & $0(0)$ & $0(0)$ & $0(0)$ & $0.483(2)$ & $0(0)$ & $0.213(2)$ & $0.377(2)$ & $0(0)$ & $0.158(2)$ & - \\
\hline
\end{tabular}




\section{Discussion}

313 This study provides a case study of a comprehensive, public sector audiology clinic in Malawi. It also 314 details the profile and clinical findings of patients attending the clinic between 2016 and 2017. Due to 315 the increasing awareness of the availability of specialist ear and hearing care services at QECH, the number of patients assessed in 2017 was double that of 2016 (Table 2).

Types and causes of hearing loss

The cause of hearing loss was unknown for the majority of patients with hearing loss $(56.7 \%$ of adults and $65.9 \%$ of children). This could be due to several reasons. Firstly, genetic testing and other aetiological investigations of hearing loss were not available at QECH. Further, even if more resources were available, it is possible that the cause would remain unknown. For instance, if an individual developed hearing loss due to an associated viral infection, it may go unnoticed until later in life making it very difficult to ascertain the origin of hearing loss from the medical history at the time of assessment. As another example, for patients with multiple health conditions, there may be numerous potential causes of hearing loss present in the same individual.

In this study, the most common identifiable cause of hearing loss in children was CSOM (18.8\%). Chronic suppurative otitis media (CSOM) is particularly prevalent, preventable cause of acquired hearing loss in school aged children $[28,29]$ and is characterised by persistent discharge from the middle ear through ear drum perforation often associated with varying levels of hearing loss [30]. Population-based studies have also found CSOM to be a very common cause of hearing loss in children in Swaziland and Botswana [31] and up to 90\% of CSOM cases can occur in low income countries [29]. A systematic review reported that $24 \%$ of preschool children had a hearing loss due to ear wax impaction [15]. Due to the nature of the clinical data presented in this study, wax impaction is not cited as a reason for hearing loss because impacted wax is removed prior to hearing assessment at QECH audiology department. According to medical files and the individual patient's medical history, $8.6 \%$ of children with hearing loss had been administered with some form of ototoxic medication. This is a higher 
than the data published by $\mathrm{WHO}$ that estimates $4 \%$ of childhood hearing losses to be attributed to ototoxic medication [32].

There are a limited number of studies detailing the clinical findings of an audiology clinic a low resource setting such as Malawi. Lasisi et al. (2006) reported results of a retrospective review of paediatric patients ( $n=713$ ), seen at an outpatient otorhinolaryngologic clinic in Ibadan, Nigeria [33] and found $14 \%$ of children had some form of sensorineural hearing loss. This was considerably lower than the results reported in the present study. Lasisi et al (2006) recognised the unrepresentatively low number of people with sensorineural hearing losses attending the otorhinolaryngologic clinic and cited potential reasons including poor access to healthcare and widespread poverty [33]. The number of children presenting with CSOM was also lower (4.9\% vs $18.8 \%)$ than reported in the present study but hearing losses associated with ototoxic medication was similar (12.6\% vs $8.6 \%$ ).

Banda et al (2018) described the clinical findings of children seen in a public sector audiology department in Botswana and reported $32 \%$ of children under 10 years of age presented with hearing loss [34]. This is similar to the proportion of similar aged children with hearing loss found in the present study (34\%). However, the number of children that present with severe to profound levels of hearing loss at audiology clinics varies in LMICs. Banda et al (2018) reported $36.6 \%$ of hearing loss in children (under 10 years of age) was severe to profound in degree [34] which is much lower than in the present study (54.8\%) and from clinic based data from rural Nicaragua (86\%) [3], when comparing children of the same age range. It is likely that parents seek ear and hearing care services for their children once their difficulties appear more apparent which might explain the high levels of severe to profound hearing loss detected at the clinic level.

(1)

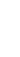

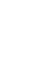


The most commonly used assessment method was PTA. Tympanometry was used to assess the middle ear function of $84 \%$ of patients and screening OAEs were used to assess $27 \%$ of patients, most likely as they are known to be quick to administer and easy to interpret. ABR, ASSR and VRA methods were seldom used. Reasons for a low number of electrophysiological tests carried out include the presence of high electrical interference in the clinic, lack of the training for clinicians to carry out ABR threshold testing and lack of locally available consumables. This highlights the need for further training and a review of the types of audiological tests used to ensure they are suitable for the clinical skills, resources and environment available in low resource settings.

\section{Hearing aid uptake}

Overall, the uptake of hearing aids was low at QECH (28.3\% of adults with hearing loss) and the number of patients fitted with hearing aids decreased from 2016 to 2017 . This was surprising due to the adequate number of trained staff and suitable audiological equipment available throughout this time frame and the low-cost nature of providing refurbished hearing aids .However, there are a number of possible reasons to account for the poor uptake. Firstly, during this timeframe, the number of people with profound hearing loss increased, particularly in the paediatric population. People with very limited residual hearing are less likely to use or benefit from hearing aid technology [35]. Furthermore, and specific to this study's population, there are some practical barriers to uptake of healthcare as shown in a study by Bright et al. (2017) which found a 3\% uptake of referrals to QECH ear and hearing care services for children residing in a district located $60 \mathrm{~km}$ away [18]. Although healthcare is free at the point of access in Malawi, Bright et al (2017) reported that families faced challenges in acquiring the necessary funds to afford indirect costs of attending hospital appointments (food, travel and accommodation) as well as feeling fearful or uncertain about the hospital itself [18]. Limited knowledge of ear and hearing health in the general population has also been reported to be a significant barrier to referral uptake in Malawi [18]. These factors, as well as the prospect of needing funds for regular visits to the hospital for hearing aid aftercare and batteries, may have also affected hearing aid uptake in the current study. 
Ramma and Sebothoma (2017) explored factors associated with seeking audiology services for people

401

402

403

404

405

406

407

408

409

410

411

412

413

414

415

416

417

418

419

420

421

422

423

424

425

426

427

428

with hearing loss in Cape Town, South Africa. Despite, audiology services being available at minimal cost in South Africa, only $21 \%$ (35/166) of individuals with hearing loss reported seeking support for their hearing loss via audiology services. The researchers found that self- perceived hearing loss was associated with higher likelihood of seeking help but other factors including age, gender, severity of hearing loss, level of education and employment status were not found to be associated [36]. Other studies have suggested that certain cultural and traditional views of medical care [37] as well as the perception that hearing loss is not considered to be a life-threatening condition [38] should be taken into account when observing reluctance to seek help.

The provision of hearing aids is one of the most common management options for people with hearing loss but hearing aid uptake varies globally. It is estimated that the hearing aid adoption rate for developed countries like the United Kingdom and United States is between $20-25 \%$ of people with hearing loss whereas in developing countries adoption rates have been estimated to be $1-8 \%[39,40]$. Hearing aid uptake is a multi-faceted issue and can be affected by cultural opinions of hearing loss, social representation of hearing aids, stigma and a general lack of awareness regarding hearing difficulties and the benefit of using hearing aid technology [38, 41]. A retrospective study reviewing audiological data ( $n=3894$ ) from an audiology clinic in Limpopo province, South Africa, found that $46 \%$ of patients $(n=1778)$ were diagnosed with disabling hearing loss between 2012 and 2014. Of these, only $15 \%$ were fitted with hearing aids [42]. In contrast to the present study, the authors cited the distribution of funding within the healthcare system as a key factor affecting hearing aid uptake as the allocated hospital budget could only cover the purchase of 272 hearing aids.

Finally, in the present study, $14.2 \%$ of children and $23.3 \%$ of adults with hearing loss were recommended a hearing aid (Table 5) but had not been fitted. This may have occurred if a patient declined a hearing aid or a hearing aid fitting was booked for a later date. If hearing aid fitting was arranged for a later date these patients would not have been included in overall number of new patients fitted with hearing aids and this may have caused an underestimation in hearing aid uptake from our sample. The clinical database needs to be updated in a timely manner in order to capture a patient's complete journey through the audiology services. 
The findings presented in this study highlight the need for further research to investigate long-term hearing aid usage and reasons for poor uptake of hearing aids at QECH. Additionally, the development of audiology clinics in rural communities could help strengthen support, raise awareness of the impact of hearing loss and ensure patients are not lost to follow up.

The QECH audiology department is the product of collaboration between local, governmental and international partners. An external organisation funded the infrastructure, equipment and training opportunities and the $\mathrm{MoH}$ now employ all staff members and the department is embedded in the hospital system. Despite this progress, there is still much work to do for these services to be sustainable. Traditionally, audiology clinics have relied on very costly technology for hearing testing and hearing aid fitting. The lack of local low-cost options makes the clinic reliant on external organisations for refurbished hearing aids and equipment donations until other options become available. Recently, WHO recommended a number of technological and workforce innovations that could lead to increased access to hearing aids in low income countries [43]. These included the use of low-cost hearing aid technology and models of community delivered hearing care [43-46]. It would be beneficial to pilot these innovations in LMICs, particularly in clinics like QECH where there are trained professionals and appropriate testing environments.

In this study, we found $6.7 \%$ of patients presented with profound hearing loss. These patients will not gain significant benefit from hearing aids but due to lack of capacity, funds and human resources, many will not have access to cochlear implantation. It is important for audiology services to maintain strong links with the education sector to help teachers better support children with hearing difficulties and allow for more timely referrals to ear, hearing care and sign language support..

There is still a significant shortage of ear and hearing care health professionals in Malawi and audiology is not an established profession. Further work is needed to raise the profile of the audiology workforce in Malawi to ensure health professionals obtain the appropriate employment positions, determined by their specialist audiology training. Additionally, when choosing candidates for audiology training programmes, candidates need the sufficient, relevant pre-training qualifications to allow them to be employed by the $\mathrm{MoH}$. Clinical staff at QECH audiology department still have regular access to remote 
support and advice from Sound Seekers management team and experienced volunteer audiologists.

The mentoring and continued clinical and counselling skills training of audiology health professionals and community health workers and the use of task shifting is vital for the continuity of healthcare in LMICs, especially in rural communities [47-49]. Bilateral mentorship between global partners and Malawian ear and hearing care professionals is particularly beneficial as the profession is emerging but still in its infancy [50]. The Vision 2020 Links programme has successfully established a network of global eye care training institutions and similar initiatives could be developed to facilitate ear care training [51].

Finally, in order for services to be sustainable, work should be carried out collaboratively between the $\mathrm{MoH}$, existing hospital staff and external organisations to encourage expansion of the current healthcare system to include audiology staffing positions, resource budgeting and succession planning. Recent work has highlighted the benefits of training community health workers in hearing screening and delivery of basic treatments in LMICs $[52,53]$ as well as the use of validated hearing screening smartphone applications in these populations $[54,55]$. These options should be explored further, with a thorough analysis of long-term cost effectiveness and reliability as well as follow up provision, to enhance access to sustainable, comprehensive ear and hearing care services.

Strengths, limitations and future work

The QECH audiology service has been successful in providing audiological care to patients in Southern Malawi since 2016. The department is supported by the Malawian MoH making it a pioneer in subSaharan Africa. A key strength of the current study is the amount of data presented including type of clinical assessment, clinical findings and intervention options for patients of all ages seen in the twoyear period. Data of this kind, from an audiology clinic in a low resource setting, is relatively rare and can serve to strengthen the processes taking place within the clinic and help the development of other services in other LMICs.

There are also some limitations. Firstly, there is a potential underestimation of conductive hearing loss present in this study. Occluding ear wax is removed prior to hearing testing and patients with flat 
administered with medical treatment. Therefore, those with possible conductive hearing loss associated with middle ear effusion and/or wax impaction are not recorded in the clinical database. Another limitation is the database is incomplete, fields including patient's residential location and type of assessment carried out were not completed for all patients included in this study. The data presented here provides a snapshot of the management options administered to patients after the initial diagnosis, including the fitting of hearing aids. However, it does not capture patients' hearing aid usage and progress. Future research should include the use of outcome measures of hearing aid benefit and analysis of the long-term impact of audiology services in LMICs, evidence in these areas is lacking in LMICs. Finally, formal impact and process evaluations of QECH Audiology services could help to understand what worked well and why in order to help others to implement similar programmes.

\section{Conclusion}

In this study, we provided a case study of a comprehensive audiology clinic in Blantyre, Malawi which could act as a service provision model for low resource settings. Results indicate a growing demand for ear and hearing care services and have identified specific training needs for clinical staff. Further research is needed to understand the reasons for the low hearing aid uptake found in this study in order to improve long term access to these services. 
517

518

519

520

521

522

523

524

525

526

527

528

529

530

531

532

533

534

535

536

537

538

539

540

541

542

543

544

545

\section{References}

1. World Health Organization. Prevention of blindness and deafness: Grades of hearing impairment 2019 [cited 06/02/2020]. Available from:

https://www.who.int/pbd/deafness/hearing impairment grades/en/.

2. Olusanya BO, Swanepoel DW, Chapchap MJ, Castillo S, Habib H, Mukari SZ, et al. Progress towards early detection services for infants with hearing loss in developing countries. BMC Health Serv Res. 2007;7:14-. doi: 10.1186/1472-6963-7-14. PubMed PMID: 17266763.

3. Saunders JE, Vaz S, Greinwald JH, Lai J, Morin L, Mojica K. Prevalence and etiology of hearing loss in rural Nicaraguan children. Laryngoscope. 2007;117(3):387-98. Epub 2007/03/06. doi: 10.1097/MLG.0b013e31802e3726. PubMed PMID: 17334299.

4. Malema KM. The Working Conditions In The Mining Sector: The Case Of Mchenga And Kaziwiziwi Coal Mines In Malawi. Open Science Journal. 2017;2.

5. Wilson BS, Tucci DL, Merson MH, O'Donoghue GM. Global hearing health care: new findings and perspectives. The Lancet. 2017;390(10111):2503-15. doi: https://doi.org/10.1016/S0140$\underline{6736(17) 31073-5 .}$.

6. Honeycutt A. Economic costs of mental retardation, cerebral palsy, hearing loss and vision impairment. In: Grosse Scott D, Barbara MA, Sharon NB, Gerry EH, Sheryl AL, editors. Using Survey Data to Study Disability: Results from the National Health Survey on Disability. Research in Social Science and Disability. 3: Emerald Group Publishing Limited; 2003. p. 207-28.

7. Lin FR, Metter EJ, O'Brien RJ, Resnick SM, Zonderman AB, Ferrucci L. Hearing loss and incident dementia. Arch Neurol. 2011;68(2):214-20. Epub 2011/02/16. doi: 10.1001/archneurol.2010.362. PubMed PMID: 21320988; PubMed Central PMCID: PMCPMC3277836.

8. Bagli Z. Multicultural aspects of hearing loss. Communication Disorders in Multicultural and International Populations. 2012:208-42. doi: 10.1016/B978-0-323-06699-0.00020-0.

9. Graydon K, Waterworth C, Miller H, Gunasekera H. Global burden of hearing impairment and ear disease. The Journal of Laryngology \& Otology. 2019;133(1):18-25. Epub 2018/07/26. doi: $10.1017 / \mathrm{S} 0022215118001275$. 
546 10. Orji A, Kamenov K, Dirac M, Davis A, Chadha S, Vos T. Global and regional needs, unmet

547 needs and access to hearing aids. Int J Audiol. 2020:1-7. Epub 2020/02/06. doi:

$548 \quad$ 10.1080/14992027.2020.1721577. PubMed PMID: 32011190.

549 11. Mulwafu W, Fagan JJ, Mukara KB, Ibekwe TS. ENT Outreach in Africa: Rules of

550 Engagement. OTO Open. 2018;2(2):2473974x18777220. Epub 2018/11/28. doi:

551 10.1177/2473974x18777220. PubMed PMID: 30480217; PubMed Central PMCID:

552 PMCPMC6239148.

553 12. National Statistics Office. Malawi Population and Housing Census: Main Report 2019

554 [updated May 2019]. 1]. Available from:

555 http://www.nsomalawi.mw/images/stories/data on line/demography/census 2018/2018\%20Malawi\%

556 20Population\%20and\%20Housing\%20Census\%20Main\%20Report.pdf.

557 13. The World Bank Group. Classifying countries by income 2019 [cited 05.05.2020]. Available

558 from: https://datatopics.worldbank.org/world-development-indicators/stories/the-classification-of-

559 countries-by-income.html.

560 14. World Health Organization. Addressing the rising prevalence of hearing loss. Geneva: World

561 Health Organization, 2018 2018. Report No.: 9789241550260.

562 15. Mulwafu W, Kuper H, Ensink RJ. Prevalence and causes of hearing impairment in Africa.

563 Trop Med Int Health. 2016;21(2):158-65. Epub 2015/11/21. doi: 10.1111/tmi.12640. PubMed PMID:

56426584722.

565 16. Hunt L, Mulwafu W, Knott V, Ndamala CB, Naunje AW, Dewhurst S, et al. Prevalence of

566 paediatric chronic suppurative otitis media and hearing impairment in rural Malawi: A cross-sectional

567 survey. PLOS ONE. 2017;12(12):e0188950. doi: 10.1371/journal.pone.0188950.

568 17. Mulwafu W, Tataryn M, Polack S, Viste A, Goplen FK, Kuper H. Children with hearing

569 impairment in Malawi, a cohort study. Bull World Health Organ. 2019;97(10):654-62. Epub

570 2019/10/28. doi: 10.2471/blt.18.226241. PubMed PMID: 31656330; PubMed Central PMCID:

571 PMCPMC6796677.

572 18. Bright T, Mulwafu W, Thindwa R, Zuurmond M, Polack S. Reasons for low uptake of referrals

573 to ear and hearing services for children in Malawi. PLoS One. 2017;12(12):e0188703. Epub

574 2017/12/21. doi: 10.1371/journal.pone.0188703. PubMed PMID: 29261683; PubMed Central PMCID:

575 PMCPMC5736203. 
576 19. Mulwafu W, Ensink R, Kuper H, Fagan J. Survey of ENT services in sub-Saharan Africa: little 577 progress between 2009 and 2015. Glob Health Action. 2017;10(1):1289736. Epub 2017/05/10. doi:

578 10.1080/16549716.2017.1289736. PubMed PMID: 28485648; PubMed Central PMCID:

579 PMCPMC5496047.

580 20. Baum A, Mulwafu W, Phiri M, Polack S, Bright T. An Intervention to Improve Uptake of 581 Referrals for Children with Ear Disease or Hearing Loss in Thyolo District, Malawi: Acceptability and 582 Feasibility. Int J Environ Res Public Health. 2019;16(17):3144. doi: 10.3390/ijerph16173144. PubMed 583 PMID: 31466419.

584 21. Fagan JJ, Jacobs M. Survey of ENT services in Africa: need for a comprehensive 585 intervention. Glob Health Action. 2009;2. Epub 2009/12/23. doi: 10.3402/gha.v2i0.1932. PubMed 586 PMID: 20027268; PubMed Central PMCID: PMCPMC2779942.

587 22. Mulwafu W, Nyirenda TE, Fagan JJ, Bem C, Mlumbe K, Chitule J. Initiating and developing 588 clinical services, training and research in a low resource setting: the Malawi ENT experience. Trop 589 Doct. 2014;44(3):135-9. Epub 2014/02/27. doi: 10.1177/0049475514524393. PubMed PMID: 59024569097.

591 23. Mulwafu W, Fagan J. Improving access to hearing care services and professionals in Africa 592 through task sharing: The Malawian experience. East and Central African Journal of Surgery. $593 \quad 2019 ; 24(2): 78-81$.

594 24. Sound Seekers. Vision, Mission and Values 2019 [cited 05.05.2020]. Available from: 595 https://www.sound-seekers.org.uk/about/.

596 25. Mulwafu W, Strachan DR, Bartlett R, Caron C. Cochlear implantation in Malawi: report of the 597 first four cases. J Laryngol Otol. 2017;131(10):914-8. Epub 2017/08/16. doi:

598 10.1017/s0022215117001724. PubMed PMID: 28807077.

599 26. World Health Assembly. Prevention of deafness and hearing loss: WHA70.13. Geneva: 2017 600 Contract No.: 15.8.

601 27. World Health Organization. Deafness and hearing loss: World Health Organization; 2020 602 [cited 2020 7th April 2020]. Available from: https://www.who.int/news-room/fact603 sheets/detail/deafness-and-hearing-loss. 
604

605

606

607

608

609

610

611

612

613

614

615

616

617

618

619

620

621

622

623

624

625

626

627

628

629

630

631

632

633

28. Daly KA, Selvius RE, Lindgren B. Knowledge and attitudes about otitis media risk: implications for prevention. Pediatrics. 1997;100(6):931-6. Epub 1997/12/31. doi: 10.1542/peds.100.6.931. PubMed PMID: 9374559.

29. World Health Organization. Chronic suppurative otitis media: Burden of illness and Management Options Geneva, : Child and Adolescent Health and Development: Prevention of Blindness and Deafness, 2004.

30. Jacob A, Rupa V, Job A, Joseph A. Hearing impairment and otitis media in a rural primary school in South India. International Journal of Pediatric Otorhinolaryngology. 1997;39(2):133-8. doi: https://doi.org/10.1016/S0165-5876(96)01479-6.

31. Smith A, Hatcher J. Preventing deafness in Africa's children. Afr Health. 1992;15(1):33-5. Epub 1992/11/01. PubMed PMID: 12285914.

32. World Health Organization. Childhood hearing loss: Strategies for Prevention and Care 2016 [updated 06/02/2020]. 28]. Available from: https://www.who.int/docs/defaultsource/imported2/childhood-hearing-loss--strategies-for-prevention-and-care.pdf?sfvrsn=cbbbb3cc 0. 33. Lasisi OA, Ayodele JK, ljaduola GT. Challenges in management of childhood sensorineural hearing loss in sub-Saharan Africa, Nigeria. Int J Pediatr Otorhinolaryngol. 2006;70(4):625-9. Epub 2005/09/20. doi: 10.1016/j.ijporl.2005.08.009. PubMed PMID: 16168496.

34. Banda FM, Powis KM, Mokoka AB, Mmapetla M, Westmoreland KD, David T, et al. Hearing Impairment Among Children Referred to a Public Audiology Clinic in Gaborone, Botswana. Glob Pediatr Health. 2018;5:2333794x18770079. Epub 2018/05/16. doi: 10.1177/2333794x18770079. PubMed PMID: 29761140; PubMed Central PMCID: PMCPMC5946350.

35. Hjaldahl J, Widén S, Carlsson P-I. Severe to profound hearing impairment: factors associated with the use of hearing aids and cochlear implants and participation in extended audiological rehabilitation. Hearing, Balance and Communication. 2017;15(1):6-15. doi: $10.1080 / 21695717.2016 .1242250$.

36. Ramma L, Sebothoma B, editors. Exploring Factors Associated with a Higher Likelihood of Seeking Audiology services by Individuals with Hearing Impairment in Cape Town, South Africa2017. 37. Zhao F, Manchaiah V, St Claire L, Danermark B, Jones L, Brandreth M, et al. Exploring the influence of culture on hearing help-seeking and hearing-aid uptake. Int J Audiol. 2015;54(7):435-43. Epub 2015/03/13. doi: 10.3109/14992027.2015.1005848. PubMed PMID: 25761498. 
38. Davis A, Smith P, Ferguson M, Stephens D, Gianopoulos I. Acceptability, benefit and costs of early screening for hearing disability: a study of potential screening tests and models. Health Technol Assess. 2007;11(42):1-294. Epub 2007/10/12. doi: 10.3310/hta11420. PubMed PMID: 17927921. 39. National Sample Survey Organisation. Disabled Persons in India. India: Ministry of Statistics and Programme Implementation Government of India, 2003.

40. Wong LLN, McPherson B. Universal Hearing Health Care: China. ASHA Leader. 2008;13(17):14-. doi: 10.1044/leader.wb2.13172008.14. PubMed PMID: pub.1101704615.

41. Manchaiah V, Danermark B, Vinay, Ahmadi T, Tomé D, Krishna R, et al. Social representation of hearing aids: cross-cultural study in India, Iran, Portugal, and the United Kingdom. Clin Interv Aging. 2015;10:1601-15. doi: 10.2147/CIA.S86108. PubMed PMID: 26504376.

42. Hlayisi VG, Ramma L. Rehabilitation for disabling hearing loss: evaluating the need relative to provision of hearing aids in the public health care system. Disabil Rehabil. 2019;41(22):2704-7. Epub 2018/05/22. doi: 10.1080/09638288.2018.1473507. PubMed PMID: 29779397.

43. Yong MW, A; McMahon, C; McPherson, B; Nieman, C; Reed, N; Lin, F. Access to adults' hearing aids: policies and technologies used in eight countries. Bulletin of the World Health Organization. 2019;97:699-710.

44. Nieman CL, Marrone N, Mamo SK, Betz J, Choi JS, Contrera KJ, et al. The Baltimore HEARS Pilot Study: An Affordable, Accessible, Community-Delivered Hearing Care Intervention. Gerontologist. 2017;57(6):1173-86. Epub 2016/12/09. doi: 10.1093/geront/gnw153. PubMed PMID: 27927734; PubMed Central PMCID: PMCPMC5881797.

45. Medtronix. Shruti Case Study: Aligning Value [cited 06/02/2020]. Available from: https://www.medtronic.com/za-en/transforming-healthcare/aligning-value/perspective/case$\underline{\text { studies/shruti.html. }}$

46. World Wide Hearing. What we do: Our Solution 2017 [cited 06/02/2020]. Available from: https://www.wwhearing.org/en/our-solution/.

47. Munoz K. Counseling Skill Development in Audiology: Clinical Instruction Considerations. Seminars in hearing. 2018;39(1):9-12. Epub 2018/02/10. doi: 10.1055/s-0037-1613701. PubMed PMID: 29422709; PubMed Central PMCID: PMCPMC5802981. 
662

663

664

665

666

667

668

669

670

671

672

673

674

675

676

677

678

679

680

681

682

683

684

685

686

48. Rohatinsky N, Cave J, Krauter C. Establishing a mentorship program in rural workplaces: connection, communication, and support required. Rural and remote health. 2020;20(1):5640. Epub 2020/01/14. doi: 10.22605/rrh5640. PubMed PMID: 31928037.

49. Ekberg K, Grenness C, Hickson L. Addressing patients' psychosocial concerns regarding hearing aids within audiology appointments for older adults. Am J Audiol. 2014;23(3):337-50. Epub 2014/07/19. doi: 10.1044/2014_aja-14-0011. PubMed PMID: 25036799.

50. Vandjelovic ND, Sugihara EM, Mulwafu W, Madgy DN. The Creation of a Sustainable Otolaryngology Department in Malawi. Ear, Nose \& Throat Journal. 2019:0145561319855366. doi: $10.1177 / 0145561319855366$.

51. London School of Hygiene and Tropical Medicine ICfEH. VISION 2020 LINKS programme [cited 07.04.2020]. Available from: https://iceh.Ishtm.ac.uk/vision-2020-links-programme/.

52. Mulwafu W, Kuper H, Viste A, Goplen FK. Feasibility and acceptability of training community health workers in ear and hearing care in Malawi: a cluster randomised controlled trial. BMJ Open. 2017;7(10):e016457. doi: 10.1136/bmjopen-2017-016457.

53. O'Donovan J, Verkerk M, Winters N, Chadha S, Bhutta MF. The role of community health workers in addressing the global burden of ear disease and hearing loss: a systematic scoping review of the literature. BMJ Global Health. 2019;4(2):e001141. doi: 10.1136/bmjgh-2018-001141.

54. Yousuf Hussein S, Wet Swanepoel D, Biagio de Jager L, Myburgh HC, Eikelboom RH, Hugo J. Smartphone hearing screening in mHealth assisted community-based primary care. J Telemed Telecare. 2016;22(7):405-12. Epub 2015/10/16. doi: 10.1177/1357633×15610721. PubMed PMID: 26468215.

55. Sandstrom J, Swanepoel D, Laurent C, Umefjord G, Lundberg T. Accuracy and Reliability of Smartphone Self-Test Audiometry in Community Clinics in Low Income Settings: A Comparative Study. Ann Otol Rhinol Laryngol. 2020:3489420902162. Epub 2020/01/23. doi: 10.1177/0003489420902162. PubMed PMID: 31965808.

687 


\section{University Library}

\section{- M M N E R VA A gateway to Melbourne's research publications}

Minerva Access is the Institutional Repository of The University of Melbourne

Author/s:

Parmar, B;Phiri, M;Caron, C;Bright, T;Mulwafu, W

Title:

Development of a public audiology service in Southern Malawi: profile of patients across two years.

Date:

2021-10

Citation:

Parmar, B., Phiri, M., Caron, C., Bright, T. \& Mulwafu, W. (2021). Development of a public audiology service in Southern Malawi: profile of patients across two years.. Int J Audiol, 60 (10), pp.789-796. https://doi.org/10.1080/14992027.2020.1864486.

Persistent Link:

http://hdl.handle.net/11343/290232 